\title{
The fate of water at the electrochemical interfaces: electrochemical behavior of free water vs. coordinating water.
}

Nicolas Dubouis, ${ }^{\mathrm{a}, \mathrm{b}, \mathbb{I l}}$ Alessandra Serva, ${ }^{\mathrm{c}, \mathbb{f l}}$ Elodie Salager, ${ }^{\mathrm{b}, \mathrm{d}}$, Michael Deschamps, ${ }^{\mathrm{b}, \mathrm{d}}$ Mathieu Salanne, ${ }^{\mathrm{b}, c_{*}}$ Alexis Grimaud ${ }^{\mathrm{a}, \mathrm{b}} *$

\section{AUTHORS ADDRESS:}

${ }^{\text {a }}$ Chimie du Solide et de l'Energie, Collège de France, UMR 8260, 75231 Paris Cedex 05, France

${ }^{\mathrm{b}}$ Réseau sur le Stockage Electrochimique de 1'Energie (RS2E), CNRS FR3459, 33 rue Saint Leu, 80039 Amiens Cedex, France

${ }^{\mathrm{c}}$ Sorbonne Université, CNRS, Physico-Chimie des Électrolytes et Nanosystèmes Interfaciaux, F-75005 Paris, France

${ }^{\mathrm{d}}$ CNRS, CEMHTI UPR3079, Université d'Orléans, 1D avenue de la recherche scientifique, 45071 Orléans Cedex 2, France

" These authors contributed equally to the work

emails: mathieu.salanne@ sorbonne-universite.fr, alexis.grimaud@ college-de-france.fr 


\section{ABSTRACT:}

The water reduction which produces hydrogen is one key reaction for electrochemical energy storage. While it has been widely studied in traditional aqueous electrolytes for water splitting (electrolyzers), it also plays an important role for batteries. Indeed, the reduction of water at relatively high potential prevents the practical realization of high-voltage aqueous batteries, while water contamination is detrimental for organic batteries electrolytes. Nevertheless, recent studies pointed towards the positive effect of traces of water for Li-air batteries as well as for the formation of solid-electrolyte-interphase. Herein, we provide a detailed understanding of the role of the solvation on water reduction reaction in organic electrolytes. Using electrochemistry, classical molecular dynamics simulations and nuclear magnetic resonance spectroscopy, we were able to demonstrate that 1) the hydrophilicity/hydrophobicity of the species inside the electrochemical double-layer directly controls the reduction of water and 2) water coordinating strong Lewis acids such as $\mathrm{Li}^{+}$ cations is more reactive than "free" water (or non-coordinating) water molecules.

Table of Content

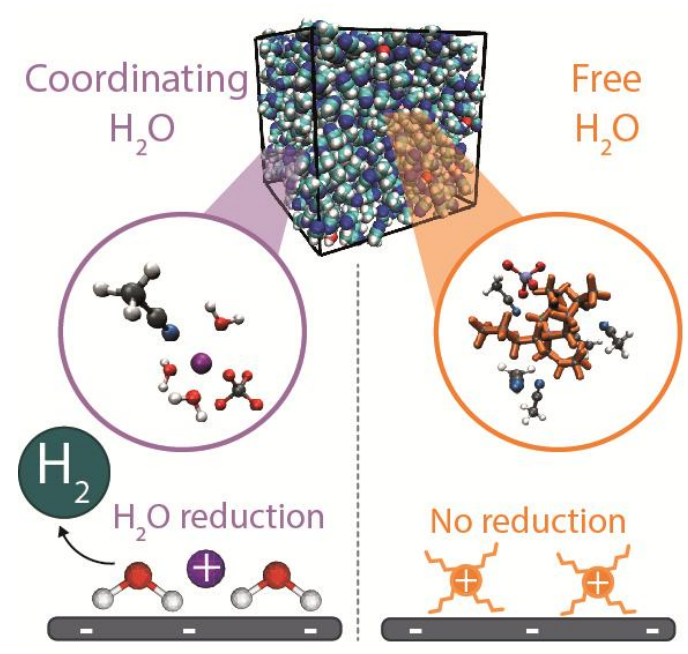




\section{Introduction}

The influence of traces of water in organic electrolytes for Li-ion batteries (LIBs) electrochemistry has been a subject of interest since their commercialization in the 90s'. Indeed, its presence is detrimental for the stability of the electrode materials and of the electrolytes and degrade the cycling performances of the system owing to its influence on the formation and the nature of the solid-electrolyte-interphase (SEI). ${ }^{1-5}$ With the goal of improving the performances of LIBs, most of studies were often focusing on the practical impact of water added into Li-containing electrolytes. Nevertheless, a regain of interest was recently observed as water traces in organic electrolytes were found to promote the performances for other battery chemistries, especially the oxygen redox chemistry which is at the heart of the lithium-air batteries, ${ }^{6-11}$ and the solvation properties of divalent cations such as Mg-ion. More recently, novel classes of safe superconcentrated aqueous or hybrid aqueous/non-aqueous electrolytes were proposed, highlighting that water redox activity would drastically be governed by its solvation (free water vs. cation-coordinating water). ${ }^{12-16}$ Thus, playing on water solvation appears as a promising strategy to tune its reactivity and help the design of new battery chemistries.

As the standard redox potential for water oxidation (OER: $\mathrm{H}_{2} \mathrm{O}=1 / 2 \mathrm{O}_{2}+2 \mathrm{H}^{+}+2 \mathrm{e}^{-}$) is relatively high and the reaction suffers from sluggish kinetics, it makes this reaction unlikely to occur at potential at which positive electrodes are working. In contrast, most efforts have been placed on the other half reaction of water electrolysis, namely the hydrogen evolution reaction (HER: $\mathrm{H}_{2} \mathrm{O}+\mathrm{e}^{-}=1 / 2 \mathrm{H}_{2}+\mathrm{OH}^{-}$), which occurs $1.23 \mathrm{~V}$ lower than water oxidation and shows a relatively fast kinetics, therefore making this reaction more likely to take place during batteries operation. The HER was largely studied in aqueous media, and its 
mechanism was shown to be drastically dependent on weak interactions that are controlled by the nature of the electrode, the $\mathrm{pH}$, the applied potential or the electrolyte composition. ${ }^{17-20}$ However, the precise role played by the solvation of water at the electrochemical interface is difficult to assess experimentally owing to the dual role played by water as reactant and as solvent. To alleviate this complexity, few studies were thus carried out in organic electrolytes and pointed towards the importance of the cation on the water reduction reaction. ${ }^{21-23}$

Intrigued by the critical role played by water solvation on its redox activity, we decided to study, in this work, the relative reactivity of free water molecules when compared to coordinating water molecules. For that, we re-investigated the redox activity of water in organic solvents. Indeed, this strategy allows to 1) tune the solvation properties of water by modifying the nature of the cation and 2) modulate the cation-water association by the use of a cation chelating agent and therefore control the relative proportion of "free" vs. coordinating water molecules. Combining electrochemical measurements with classical molecular dynamics (MD) simulations and nuclear magnetic resonance (NMR) spectroscopy, we demonstrate that the solvation strength of water molecules in the bulk of the electrolyte is largely correlated to its presence at the electrochemical interface. As a result, we could highlight that the free water molecules are less reactive than the coordinating ones at a negatively polarized electrode. This finding opens new avenues for tuning the redox activity of water in organic solvents to either develop moisture sensitive organic systems or aqueous batteries with enhanced performances.

Influence of the supporting cation on water reduction. Prior to discuss the effect of solvation structure on the water reduction, it is worth mentioning that two mechanisms exist for the HER. Indeed, in dry ACN with $10 \mathrm{mM} \mathrm{HClO}_{4}$ a first peak is observed at around $0 \mathrm{~V}$ 
vs. SHE, similarly to what is measured in water with $10 \mathrm{mM} \mathrm{HClO}_{4}$ (Figure 1). This first peak therefore involves the reduction of protons. By adding $\mathrm{H}_{2} \mathrm{O}$ into $\mathrm{ACN}$, a second reduction event is seen starting at a more negative potential at around $-0.75 \mathrm{~V}$ vs. SHE. This second event, that occurs at a similar potential than what is measured in water-based electrolyte, is associated with the splitting of water molecules and is characterized by a greater overpotential as a result of the energy penalty required to break $\mathrm{O}-\mathrm{H}$ bonds from water. ${ }^{18,20}$ These two mechanisms are therefore ubiquitous and coexist in aqueous electrolytes for $\mathrm{pH}>2,{ }^{18,20}$ as well as in organic electrolytes as shown Figure 1, with the difference that a peak which intensity depends on the amount of $\mathrm{H}_{2} \mathrm{O}$ is visible in organic electrolytes due to the limited concentration of water when compared to aqueous solution and/or the precipitation of a passivation layer. (see discussion below) Finally, we can conclude that in the absence of protons, water reduction is expected to take place well below $0 \mathrm{~V}$ vs. RHE in organic electrolytes, independently of the solvation structure and the nature of the cation. 


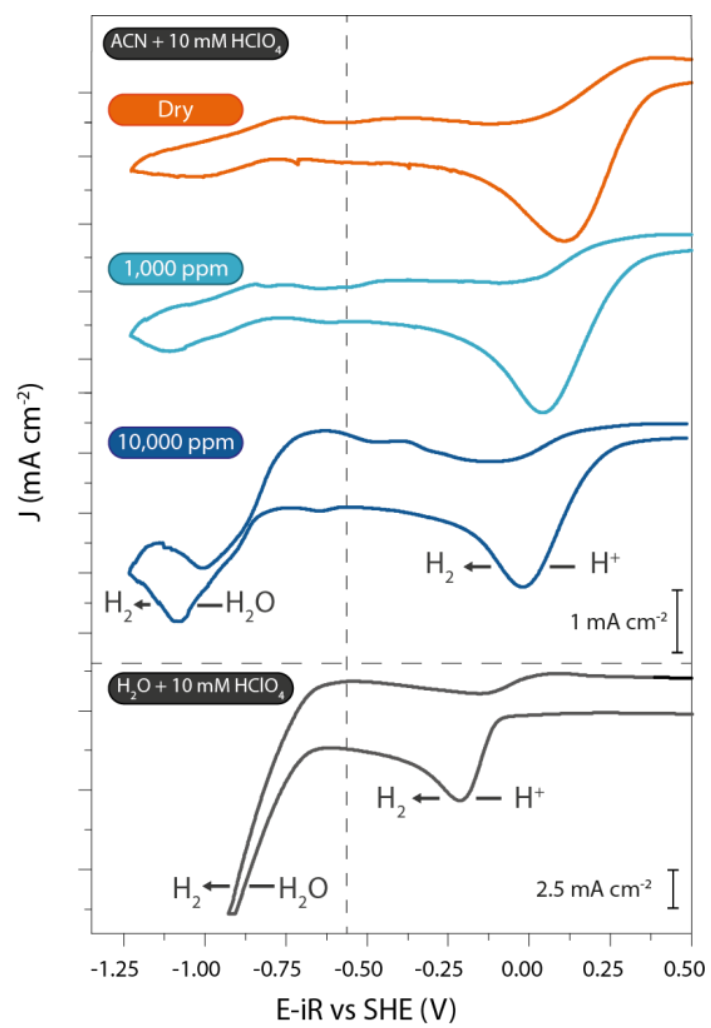

Figure 1. Cyclic voltammograms recorded at $50 \mathrm{mV} \cdot \mathrm{s}^{-1}$ on a platinum electrode in electrolytes containing $10 \mathrm{mM} \mathrm{HClO}_{4}$ and $90 \mathrm{mM} \mathrm{LiClO}_{4}$ in 1) "dry" acetonitrile (orange) 2) acetonitrile $+1,000 \mathrm{ppm}$ of water added (light blue) 3) acetonitrile $+10,000 \mathrm{ppm}$ of water added (dark blue) and 4) in water (black). Potentials are compensated for the ohmic drop (E-iR) and reported versus the Standard Hydrogen Electrode (SHE).

We then investigated the effect of cation hydrophilicity on the reduction of water in acetonitrile in the presence of 10,000 ppm $(\sim 400 \mathrm{mM})$ of water (Figure 2$)$. Interestingly, three different electrochemical behaviors can be distinguished. While almost no cathodic current was observed with tetrabutylammonium $\left(\mathrm{TBA}^{+}\right)$cations (orange), a large cathodic current was measured with $\mathrm{Li}^{+}$(purple) and $\mathrm{Na}^{+}$(green) cations. Comparing these results with dry electrolytes for which no cathodic current is measured (Figure S1) and with the result obtained in aqueous electrolyte where a reduction event is measured in a similar potential range $(<-0.75 \mathrm{~V}$ vs. NHE) (Figure 1), this cathodic current can be attributed to water 
reduction: $\mathrm{H}_{2} \mathrm{O}+\mathrm{e}^{-}=1 / 2 \mathrm{H}_{2}+\mathrm{OH}^{-}$. Second, the shape for the reduction current was found dependent on the cation. Hence, a reduction wave is observed for $\mathrm{Na}^{+}$while a reduction peak is seen for $\mathrm{Li}^{+}$cations. This difference is explained by the formation of a passivation layer (the so-called solid electrolyte interphase SEI). This passivation layer could result from the reaction of $\mathrm{Li}^{+}$with $\mathrm{OH}^{-}$formed upon water reduction and the subsequent precipitation of $\mathrm{LiOH}\left(\mathrm{Li}^{+}+\mathrm{H}_{2} \mathrm{O}+\mathrm{e}^{-}=1 / 2 \mathrm{H}_{2}+\mathrm{LiOH}_{(\mathrm{s})}\right)$, as previously observed in similar systems, ${ }^{2,24,25}$ or from the possible reactivity of the organic solvent with $\mathrm{OH}^{-}$. In both case, $\mathrm{NaOH}$ or any other Na-based product formed upon reduction is too soluble to passivate the electrode surface owing to the weaker affinity (weaker Lewis acidity) of $\mathrm{Na}^{+}$cations with hydroxile anions or other anions than $\mathrm{Li}^{+}$cations. ${ }^{24,26}$

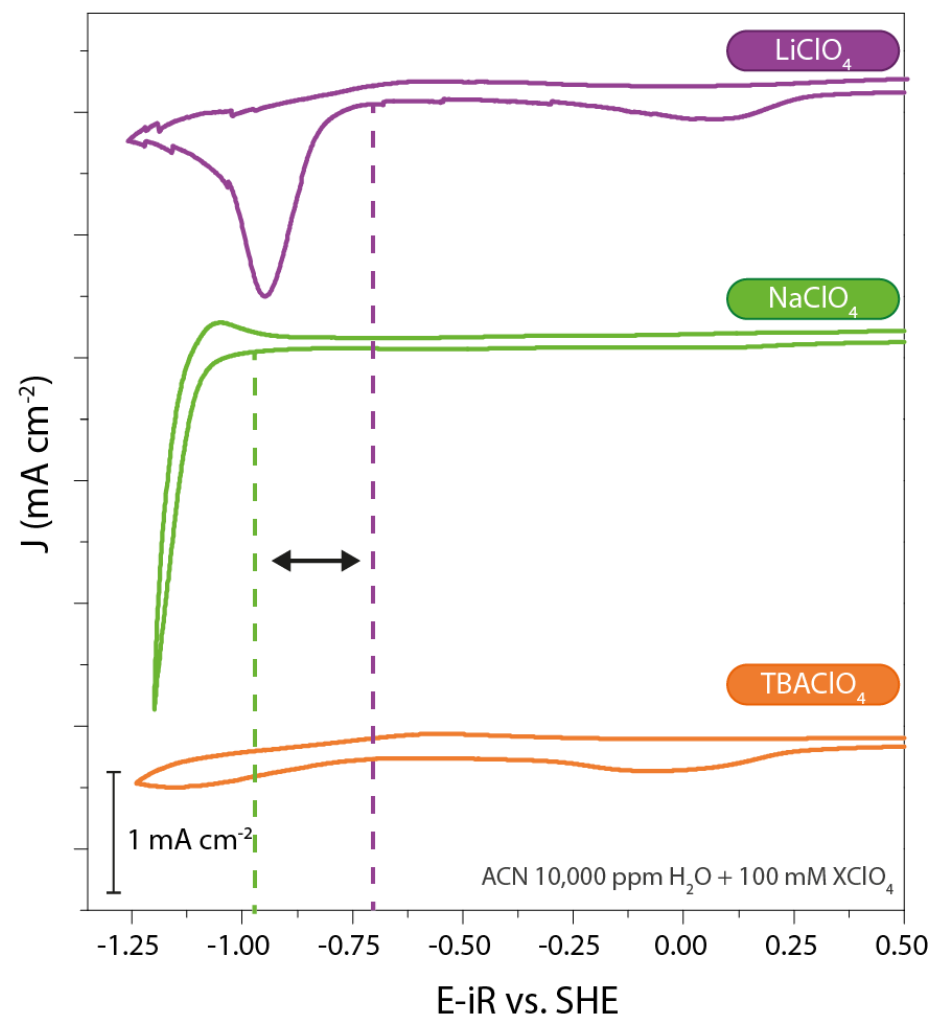

Figure 2. Cyclic voltammograms recorded over a Platinum electrode in acetonitrile electrolytes containing 10,000 ppm of water, in presence of $\mathrm{LiClO}_{4}$ (purple), $\mathrm{NaClO}_{4}$ (green), 
or $\mathrm{TBAClO}_{4}$ (orange). Potentials are compensated for the ohmic drop (E-iR) and reported versus the Standard Hydrogen Electrode (SHE).

Intrigued by this difference of reactivity for water upon reductive conditions, the solvation structure for water molecules was analyzed for the different supporting salts by classical MD simulations. To shed light on the cations first solvation shell, the radial distribution functions (RDFs) between the cations and the oxygen atom of water molecules were then calculated (Figure $3 \mathrm{a}$ ). $\mathrm{Li}^{+}$and $\mathrm{Na}^{+}$cations have a stable first solvation shell (very sharp first peak in the RDFs), while only a broad low intensity peak at long distances is observed for the $\mathrm{TBA}^{+}$cation. In particular, the $\mathrm{Li}-\mathrm{O}_{\text {water }}$ and $\mathrm{Na}-\mathrm{O}_{\text {water }}$ first shell distances obtained in this work are $2.06 \AA$ and $2.38 \AA$, respectively, consistent with those previously reported in the literature for aqueous solutions. ${ }^{27-29} \mathrm{~A}$ good agreement was also found for Cation- $\mathrm{N}_{\mathrm{ACN}}$ as shown in Figure S2. ${ }^{28,30}$ The number of water molecules in the first solvation shell of the cation is rather large (about 2.7) for $\mathrm{Li}^{+}$, it slightly decreases for $\mathrm{Na}^{+}$and finally goes almost to zero for $\mathrm{TBA}^{+}$cation, which shows the possibility of accommodating a larger number of organic solvent molecules in its solvation shell (see Figure 3b). The direct consequence is that the percentage of "free" water molecules rapidly increases moving from $\mathrm{Li}^{+}$to $\mathrm{Na}^{+}$and finally to $\mathrm{TBA}^{+}$cation, as shown in Figure $3 \mathrm{c}$. The different complexing ability of the three cations with water thus reveals a different hydrophilic character following $\mathrm{Li}^{+}>$ $\mathrm{Na}^{+}>\mathrm{TBA}^{+}$. The marked passage from hydrophilic $\mathrm{Li}^{+}$cation to hydrophobic $\mathrm{TBA}^{+}$cation is also confirmed by the evaluation of the cation-water cage lifetime (Figure 3c and Figure S3), that indeed is one order of magnitude larger for $\mathrm{Li}^{+}$and $\mathrm{Na}^{+}$than for $\mathrm{TBA}^{+}$, suggesting a reduced (almost zero) cation- $\mathrm{H}_{2} \mathrm{O}$ affinity for the $\mathrm{TBA}^{+}$cation. 

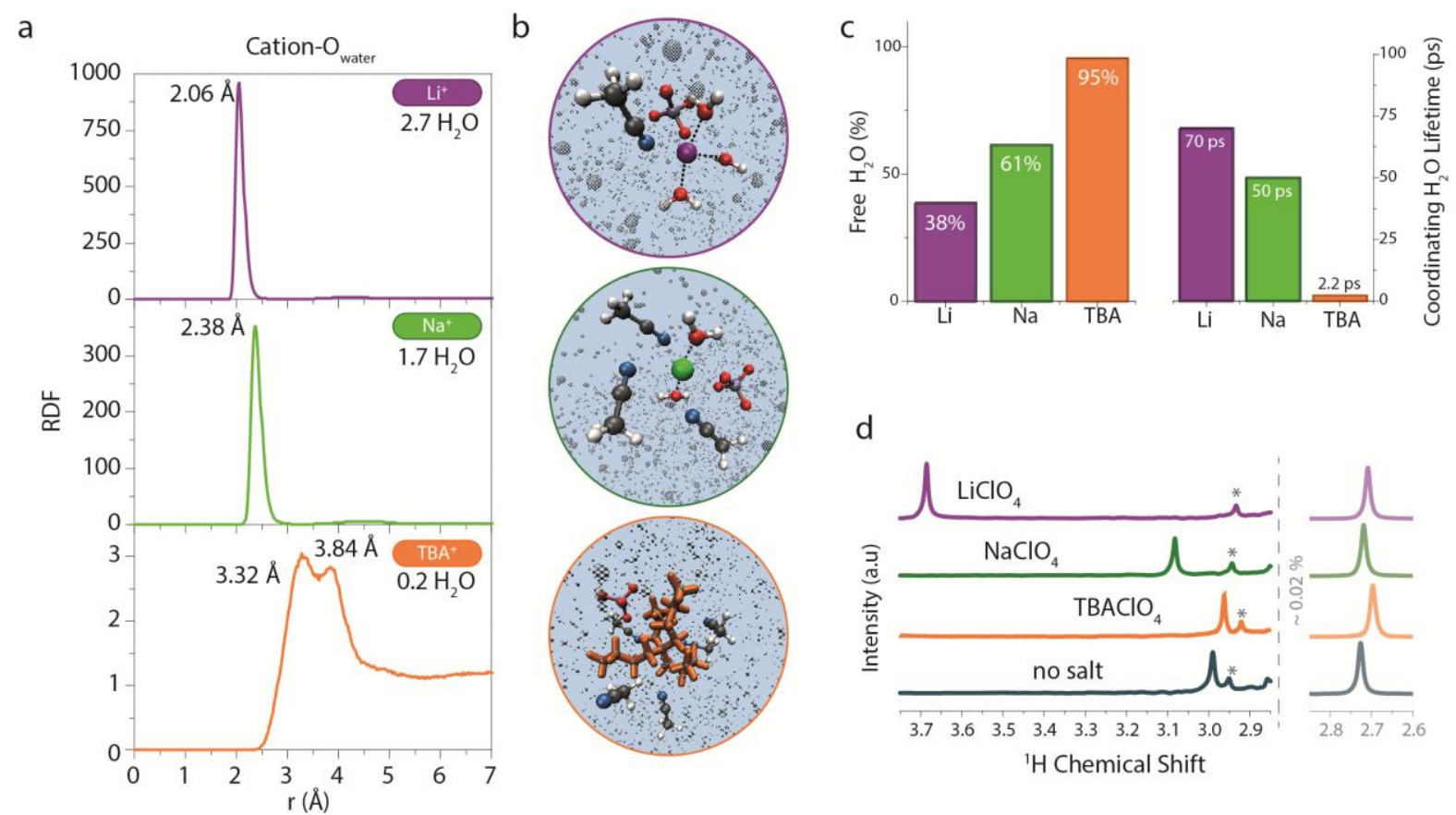

Figure 3. Influence of the cation nature $\left(\mathrm{Li}^{+}\right.$: purple, $\mathrm{Na}^{+}$: green and $\mathrm{TBA}^{+}$: orange $)$in acetonitrile electrolytes containing $100 \mathrm{mM}$ of supporting perchlorate salt and 10,000 ppm of water. a) Cation- $\mathrm{O}_{\text {water }}$ radial distribution functions, b) snapshots of corresponding MD simulations illustrating the cation first solvation shell, c) percentage of free water (left) and water molecules lifetime (ps) in the cation first solvation shell (right) and d) NMR spectra of corresponding electrolytes with the peaks corresponding to acetonitrile labeled *.

To experimentally assess these different interactions of water with the aforementioned cations, ${ }^{1} \mathrm{H}$ nuclear magnetic spectroscopy (NMR) was employed (Figure $3 \mathrm{~d}$ ). The ${ }^{1} \mathrm{H}$ signal from $\mathrm{H}_{2} \mathrm{O}$ is found for $\mathrm{TBA}^{+}(2.95 \mathrm{ppm})$ to not drastically differ from the one of water in acetonitrile without any added salt (3.0 ppm). In contrast, it is found at higher chemical shifts (downfield) for $\mathrm{Na}^{+}$(3.1 ppm), and this shift is even greater for $\mathrm{Li}^{+}$(3.7 ppm). Since a downfield signal (higher chemical shift) traduces a weaker electronic density around protons, this observation corroborates a stronger $\mathrm{Li}^{+}-\mathrm{H}_{2} \mathrm{O}$ interaction than $\mathrm{Na}^{+}-\mathrm{H}_{2} \mathrm{O}$. Instead, almost no interaction is observed between the hydrophobic $\mathrm{TBA}^{+}$cation and $\mathrm{H}_{2} \mathrm{O}$ molecules. This 
experimental observation for the increased cation- $\mathrm{H}_{2} \mathrm{O}$ affinity (or hydrophilicity) following $\mathrm{Li}^{+}>\mathrm{Na}^{+}>\mathrm{TBA}^{+}$is in agreement with the predictions made by MD simulations (Figure 3c). As a result, this spectroscopic study demonstrates that the lower electronic density observed around protons for solvated $\mathrm{Li}^{+}$cations is due to the strong Lewis acidity of $\mathrm{Li}^{+}$cations, which also suggests a greater Brønsted acidity for these protons due to electron withdrawing from the water molecule.

Having demonstrated the different hydrophilicity for the cations considered in this work, its impact on the water reduction reaction can then be rationalized. As the electrode is negatively polarized, cations are migrating with their solvation shells toward the negative electrode. In the presence of $\mathrm{TBA}^{+}$cations, the resulting double-layer is hydrophobic (as shown by the short lifetime of water molecules in its first solvation shell, Figure 3c) and water cannot access the surface of the electrode even though the concentration of free water is found greater than for $\mathrm{Li}^{+}$and $\mathrm{Na}^{+}$cations. This explains the absence of cathodic current associated with the reduction of water for $\mathrm{TBA}^{+}$(Figure 2). On the contrary, hydrophilic lithium and to lesser extent sodium cations migrate to the electrochemical interface together with their solvation shell comprised of water molecules, allowing water to be reduced. Furthermore, not only the nature of the cation dictates the presence of water at the electrochemical interface, but the cation affinity for water also modifies the onset potential for water reduction. Hence, the considerable difference in the onset potential for $\mathrm{H}_{2} \mathrm{O}$ reduction measured for $\mathrm{Li}^{+}$and $\mathrm{Na}^{+}$ cations $(\sim 250 \mathrm{mV})$ in Figure 2 cannot fully be explained by the difference of water content or lifetime of water molecules in the cations solvation shell. Indeed, such a potential shift would result, applying the Nernst equation, in an interfacial concentration of water 4 orders of magnitude greater for lithium than for sodium, while MD simulations demonstrate that the ratio of water in the solvation shell of $\mathrm{Li}^{+}$and $\mathrm{Na}^{+}$cations is closer to $1.6: 1$ and the lifetime of water molecules in the solvation shell is not drastically modified (Figure 3c). Thus, this 
difference in onset potential is likely to originate from pure kinetics limitations. As the initial Volmer step $\left(\mathrm{H}_{2} \mathrm{O}+\mathrm{e}^{-}=\mathrm{H}_{\mathrm{ads}}+\mathrm{OH}^{-}\right)$is expected to be the rate determining step for water reduction in these experimental conditions, ${ }^{18,21,26}$ the electrochemical activity is going to be driven by its activation energy that, according to the linear free energy relationship approximation, must vary linearly with the difference of energy between the products states and the reactants states of this step. ${ }^{32}$ The greater electronic withdrawing interaction between $\mathrm{Li}^{+}$cations and oxygen atom from $\mathrm{H}_{2} \mathrm{O}$ could thus be partly responsible for a weakening of the $\mathrm{O}-\mathrm{H}$ bond of water molecules (destabilization of the reactants state), in agreement with the ${ }^{1} \mathrm{H}$ NMR results that show more acidic protons (Figure $3 \mathrm{~d}$ ). This effect would thus facilitate water reduction by lowering the transition state energy as a result of an easier proton adsorption and a stronger association of $\mathrm{Li}^{+}$with $\mathrm{OH}^{-}$produced during the HER (stabilization of the products state). As divalent cations such as $\mathrm{Mg}^{2+}$, which are more hydrophilic than monovalent ones, are used, this effect becomes even more important since the measured water reduction potential is less negative (Figure S4). Finally, we could show that the nature of the organic solvent on the double-layer formation and water reduction is weak. For that, ACN was replaced by a solvent with a greater dielectric constant, namely ethylene carbonate (EC) dissolved into dimethyl carbonate (DMC), and similar electrochemical observations were made with the presence of a reduction event starting at around $-0.75 \mathrm{~V}$ vs. SHE with $\mathrm{Li}^{+}$while no reduction is observed with $\mathrm{TBA}^{+}$(Figure S5). This result confirms that organic solvent molecules play a minor role under negative polarization at the electrochemical interface when compared to the role played by cations. In other words, the concentration of water is always greater at the electrochemical interface than in the bulk of the electrolyte independently of the polarizability of the solvent. 
"Free water" vs. cation-coordinating water. Having established that the use of hydrophilic cations such as $\mathrm{Li}^{+}$enables an easy reduction of water at the electrochemical interface under negative polarization, we then investigated the reactivity of "free" water molecules in organic solvent independently of the use of hydrophobic cation. For that, crown ether (12-Crown-4) was used as an additive to selectively "trap" $\mathrm{Li}^{+}$cations and therefore release water molecules from their solvation shell, thus making them "free". We first validated this strategy by studying the water solvation using ${ }^{7} \mathrm{Li}$ and ${ }^{1} \mathrm{H}$ NMR (Figure $4 \mathrm{a}$ ). As the crown ether/Li ${ }^{+}$ratio increases closer to 1 , the chemical shift for ${ }^{7} \mathrm{Li}$ was found to be downfield (higher chemical shift), indicating a change of the $\mathrm{Li}^{+}$solvation shell and its association with the crown ether molecules. ${ }^{33}$ The opposite trend was found for the ${ }^{1} \mathrm{H}$ signal from $\mathrm{H}_{2} \mathrm{O}$ for which the chemical shift undertakes an upfield, demonstrating a greater electronic density. From these observations, it can be concluded that "free" water molecules are released when adding 12Crown-4 to the electrolyte following the reaction: $\left[\mathrm{Li}\left(\mathrm{H}_{2} \mathrm{O}\right)_{\mathrm{x}}\right]^{+}+$crown $->\left[\mathrm{Li}(\mathrm{Crown})_{1}\right]^{+}+\mathrm{x}$ $\mathrm{H}_{2} \mathrm{O}$ "free". The electrochemical behavior of these solutions was then studied, and a shift to more negative potentials as well as a decrease of the cathodic current were found with increasing 12-Crown-4 concentration (Figure 4b). Hence, we can conclude that "free" water molecules are more difficult to reduce than "coordinating" water molecules in organic media, as seen by the more negative potential required for their reduction. This finding is in agreement with the results discussed above for which water molecules strongly coordinating hydrophilic Lewis acid such as $\mathrm{Li}^{+}$cations were found to be reduced at lower onset potentials. Furthermore, we can tentatively assign the decrease of the reduction peak intensity to a reduced concentration of "free" water molecules at the electrochemical interface when compared to $\left[\mathrm{Li}\left(\mathrm{H}_{2} \mathrm{O}\right)_{\mathrm{x}}\right]^{+}$. 
a

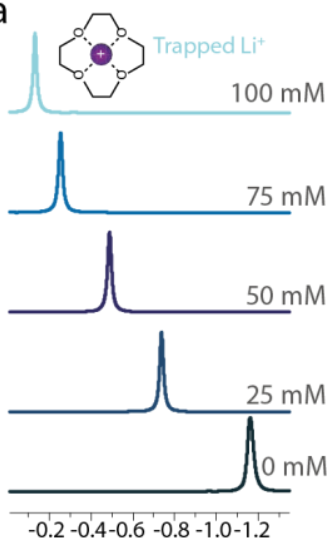

$\delta^{7} \mathrm{Li}(\mathrm{ppm})$

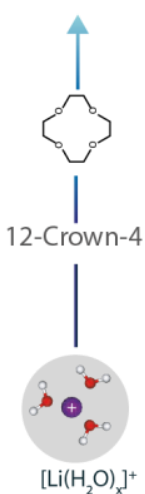

$\left[\mathrm{Li}\left(\mathrm{H}_{2} \mathrm{O}\right)_{x}\right]^{+}$

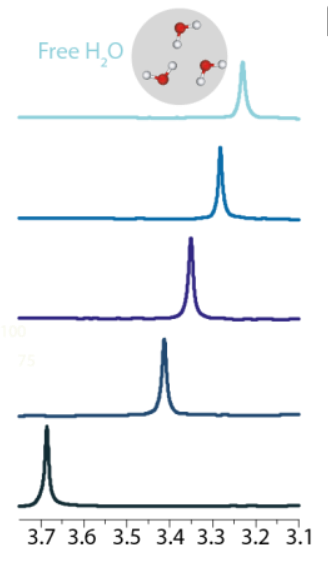

$\delta^{1} \mathrm{H}(\mathrm{ppm})$ b

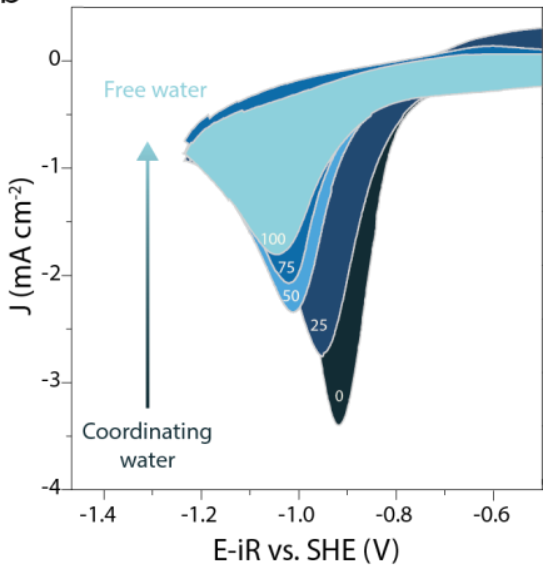

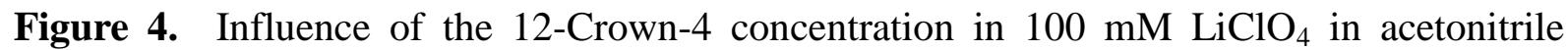
containing 10,000 ppm of water electrolytes on a) $\mathrm{Li}^{+}$(left) and $\mathrm{H}_{2} \mathrm{O}$ (right) NMR chemical shifts and b) water reduction electrochemistry.

\section{Conclusions}

Combining electrochemical and NMR spectroscopy measurements with molecular dynamics simulations, we could demonstrate that the ability of water to solvate cations dictates its electrochemical reduction. Indeed, upon negative polarization cations migrate to the electrochemical interface with their solvation shell. For hydrophilic cations such as $\mathrm{Li}^{+}$or $\mathrm{Na}^{+}$, water can thus be reduced while we could demonstrate that the use of hydrophobic cations such as large organic cations almost suppresses the water reduction. Not only the affinity of cation with water is critical, but a stronger Lewis acid cation such as $\mathrm{Li}^{+}$weakens the $\mathrm{O}-\mathrm{H}$ bond of water molecules thus lowering the energy barrier required for the hydrogen evolution reaction. This effect is further exemplified when chelating $\mathrm{Li}^{+}$with crown ether molecules to release so-called "free" water molecules that, as we demonstrate, require a greater overpotential to be reduced than molecules participating to cation solvation shell. Based on this conclusion, the use of highly concentrated $\mathrm{Li}^{+}$-based aqueous electrolytes would 
certainly not lead to an extension of the cathodic part of the electrochemical window of water, as it would instead increase the amount of coordinating water molecules with weakened $\mathrm{O}$ $\mathrm{H}$ bonds present at the electrochemical interface. ${ }^{34-36}$ Rather, the use of hydrophobic ions and/or coating strategies ${ }^{37}$ should be privileged for developing aqueous batteries with enhanced performances as it repulses water away from the electrochemical interface and thus prevents its reduction. However, water can be used as an additive in organic electrolytes as its reduction can trigger the formation of degradation products that can passivate the negative electrode. Alternatively, this understanding of the cationic influence on water reduction may also rationalize the detrimental role of water sometimes observed in metal plating experiments. Eventually, more remains to be done to understand both the kinetics and thermodynamics origin for such effect in order to implement this strategy into electrochemical energy storage devices.

\section{Supporting information}

Material and methods, molecular dynamics simulation methods, figures S1 to S5

\section{Conflicts of Interest}

The authors declare no conflict of interest.

\section{Acknowledgments}


N.D. acknowledges scholarship from Ecole Normale Supérieure. A.G. acknowledges

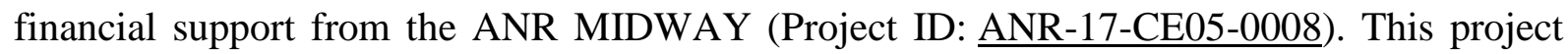
has received funding from the European Research Council (ERC) under the European Union's Horizon 2020 research and innovation program (grant agreement No. 771294).

\section{References}

(1) Aurbach, D. The Electrochemical Behavior of Lithium Salt Solutions of $\gamma$-Butyrolactone with Noble Metal Electrodes. J. Electrochem. Soc. 1989, 136 (4), 906913.

(2) Aurbach, D.; Daroux, M.; Faguy, P.; Yeager, E. The Electrochemistry of Noble Metal Electrodes in Aprotic Organic Solvents Containing Lithium Salts. J. Electroanal. Chem. Interfacial Electrochem. 1991, 297 (1), 225-244.

(3) Aurbach, D. The Correlation Between the Surface Chemistry and the Performance of Li-Carbon Intercalation Anodes for Rechargeable "Rocking-Chair" Type Batteries. $J$. Electrochem. Soc. 1994, 141 (3), 603.

(4) Aurbach, D.; Weissman, I.; Schechter, A.; Cohen, H. X-Ray Photoelectron Spectroscopy Studies of Lithium Surfaces Prepared in Several Important Electrolyte Solutions. A Comparison with Previous Studies by Fourier Transform Infrared Spectroscopy. Langmuir 1996, 12 (16), 3991-4007.

(5) $\mathrm{Xu}, \mathrm{K}$. Electrolytes and Interphases in Li-Ion Batteries and Beyond. Chem. Rev. 2014, 114 (23), 11503-11618.

(6) Meini, S.; Piana, M.; Tsiouvaras, N.; Garsuch, A.; Gasteiger, H. A. The Effect of Water on the Discharge Capacity of a Non-Catalyzed Carbon Cathode for Li-O2 Batteries. Electrochem. Solid-State Lett. 2012, 15 (4), A45-A48.

(7) Aetukuri, N. B.; McCloskey, B. D.; García, J. M.; Krupp, L. E.; Viswanathan, V.; Luntz, A. C. Solvating Additives Drive Solution-Mediated Electrochemistry and Enhance Toroid Growth in Non-Aqueous $\mathrm{Li}-\mathrm{O}_{2}$ Batteries. Nat. Chem. 2015, 7 (1), 5056.

(8) Staszak-Jirkovský, J.; Subbaraman, R.; Strmcnik, D.; Harrison, K. L.; Diesendruck, C. E.; Assary, R.; Frank, O.; Kobr, L.; Wiberg, G. K. H.; Genorio, B.; et al. Water as a Promoter and Catalyst for Dioxygen Electrochemistry in Aqueous and Organic Media. ACS Catal. 2015, 5 (11), 6600-6607.

(9) Liu, T.; Leskes, M.; Yu, W.; Moore, A. J.; Zhou, L.; Bayley, P. M.; Kim, G.; Grey, C. P. Cycling Li-O2 Batteries via LiOH Formation and Decomposition. Science 2015, 350 (6260), 530-533.

(10) Aurbach, D.; McCloskey, B. D.; Nazar, L. F.; Bruce, P. G. Advances in Understanding Mechanisms Underpinning Lithium-air Batteries. Nat. Energy 2016, 1 (9), 16128. 
(11) Liu, T.; Frith, J. T.; Kim, G.; Kerber, R. N.; Dubouis, N.; Shao, Y.; Liu, Z.; Magusin, P. C. M. M.; Casford, M. T. L.; Garcia-Araez, N.; et al. The Effect of Water on Quinone Redox Mediators in Nonaqueous Li-O2 Batteries. J. Am. Chem. Soc. 2018, 140 (4), 1428-1437.

(12) Suo, L.; Borodin, O.; Gao, T.; Olguin, M.; Ho, J.; Fan, X.; Luo, C.; Wang, C.; Xu, K. "Water-in-Salt" Electrolyte Enables High-Voltage Aqueous Lithium-Ion Chemistries. Science 2015, 350 (6263), 938-943.

(13) Suo, L.; Borodin, O.; Sun, W.; Fan, X.; Yang, C.; Wang, F.; Gao, T.; Ma, Z.; Schroeder, M.; von Cresce, A.; et al. Advanced High-Voltage Aqueous Lithium-Ion Battery Enabled by "Water-in-Bisalt" Electrolyte. Angew. Chem. Int. Ed. 2016, 55 (25), 7136-7141.

(14) Yamada, Y.; Usui, K.; Sodeyama, K.; Ko, S.; Tateyama, Y.; Yamada, A. Hydrate-Melt Electrolytes for High-Energy-Density Aqueous Batteries. Nat. Energy 2016, 1 (10), 16129.

(15) Leonard, D. P.; Wei, Z.; Chen, G.; Du, F.; Ji, X. Water-in-Salt Electrolyte for Potassium-Ion Batteries. ACS Energy Lett. 2018, 3 (2), 373-374.

(16) Wang, F.; Borodin, O.; Ding, M. S.; Gobet, M.; Vatamanu, J.; Fan, X.; Gao, T.; Edison, N.; Liang, Y.; Sun, W.; et al. Hybrid Aqueous/Non-Aqueous Electrolyte for Safe and High-Energy Li-Ion Batteries. Joule 2018, 2 (5), 927-937.

(17) Subbaraman, R.; Tripkovic, D.; Strmcnik, D.; Chang, K.-C.; Uchimura, M.; Paulikas, A. P.; Stamenkovic, V.; Markovic, N. M. Enhancing Hydrogen Evolution Activity in Water Splitting by Tailoring $\mathrm{Li}^{+}-\mathrm{Ni}(\mathrm{OH})_{2}$-Pt Interfaces. Science 2011, 334 (6060), 1256-1260.

(18) Strmcnik, D.; Uchimura, M.; Wang, C.; Subbaraman, R.; Danilovic, N.; van der Vliet, D.; Paulikas, A. P.; Stamenkovic, V. R.; Markovic, N. M. Improving the Hydrogen Oxidation Reaction Rate by Promotion of Hydroxyl Adsorption. Nat. Chem. 2013, 5 (4), 300-306.

(19) Ledezma-Yanez, I.; Wallace, W. D. Z.; Sebastián-Pascual, P.; Climent, V.; Feliu, J. M.; Koper, M. T. M. Interfacial Water Reorganization as a pH-Dependent Descriptor of the Hydrogen Evolution Rate on Platinum Electrodes. Nat. Energy 2017, 2 (4), 17031.

(20) Dubouis, N.; Yang, C.; Beer, R.; Ries, L.; Voiry, D.; Grimaud, A. Interfacial Interactions as an Electrochemical Tool To Understand Mo-Based Catalysts for the Hydrogen Evolution Reaction. ACS Catal. 2018, 8 (2), 828-836.

(21) Suárez-Herrera, M. F.; Costa-Figueiredo, M.; Feliu, J. M. Voltammetry of Basal Plane Platinum Electrodes in Acetonitrile Electrolytes: Effect of the Presence of Water. Langmuir 2012, 28 (11), 5286-5294.

(22) Ledezma-Yanez, I.; Díaz-Morales, O.; Figueiredo, M. C.; Koper, M. T. M. Hydrogen Oxidation and Hydrogen Evolution on a Platinum Electrode in Acetonitrile. ChemElectroChem 2015, 2 (10), 1612-1622.

(23) Ledezma-Yanez, I.; Koper, M. T. M. Influence of Water on the Hydrogen Evolution Reaction on a Gold Electrode in Acetonitrile Solution. J. Electroanal. Chem. 2017, 793, 18-24.

(24) Irr, L. G. Voltammetric Studies of Lithium Salt-Acetonitrile Solutions Containing Traces of Water. Electrochimica Acta 1984, 29 (1), 1-5.

(25) Dubouis, N.; Lemaire, P.; Mirvaux, B.; Salager, E.; Deschamps, M.; Grimaud, A. The Role of the Hydrogen Evolution Reaction in the Solid-electrolyte Interphase Formation Mechanism for "Water-in-Salt" Electrolytes. Energy Environ. Sci. 2018.

(26) Lutz, L.; Alves Dalla Corte, D.; Tang, M.; Salager, E.; Deschamps, M.; Grimaud, A.; Johnson, L.; Bruce, P. G.; Tarascon, J.-M. Role of Electrolyte Anions in the Na-O2 
Battery: Implications for $\mathrm{NaO} 2$ Solvation and the Stability of the Sodium Solid Electrolyte Interphase in Glyme Ethers. Chem. Mater. 2017, 29 (14), 6066-6075.

(27) Newsome, J. R.; Neilson, G. W.; Enderby, J. E. Lithium Ions in Aqueous Solution. J. Phys. C Solid State Phys. 1980, 13 (32), L923.

(28) Cartailler, T.; Kunz, W.; Turq, P.; Bellisent-Funel, M.-C. Lithium Bromide in Acetonitrile and Water: A Neutron Scattering Study. J. Phys. Condens. Matter 1991, 3 (47), 9511.

(29) Mähler, J.; Persson, I. A Study of the Hydration of the Alkali Metal Ions in Aqueous Solution. Inorg. Chem. 2012, 51 (1), 425-438.

(30) Spångberg, D.; Hermansson, K. The Solvation of Li+ and $\mathrm{Na}+$ in Acetonitrile from $\mathrm{Ab}$ Initio-Derived Many-Body Ion-solvent Potentials. Chem. Phys. 2004, 300 (1), 165176.

(31) Shinagawa, T.; Garcia-Esparza, A. T.; Takanabe, K. Insight on Tafel Slopes from a Microkinetic Analysis of Aqueous Electrocatalysis for Energy Conversion. Sci. Rep. 2015, 5, 13801.

(32) Gileadi, E. Physical Electrochemistry; Wiley-VCH Verlag GmbH \& Co. KGaA, 2011.

(33) Masiker, M. C.; Mayne, C. L.; Boone, B. J.; Orendt, A. M.; Eyring, E. M. 7Li NMR Chemical Shift Titration and Theoretical DFT Calculation Studies: Solvent and Anion Effects on Second-Order Complexation of 12-Crown-4 and 1-Aza-12-Crown-4 with Lithium Cation in Several Aprotic Solvents. Magn. Reson. Chem. MRC 2010, 48 (2), 94-100.

(34) Vatamanu, J.; Borodin, O. Ramifications of Water-in-Salt Interfacial Structure at Charged Electrodes for Electrolyte Electrochemical Stability. J. Phys. Chem. Lett. 2017, 8 (18), 4362-4367.

(35) Li, Z.; Jeanmairet, G.; Mendez-Morales, T.; Rotenberg, B.; Salanne, M. Capacitive Performance of Water-in-Salt Electrolyte in Supercapacitors: A Simulation Study. figshare 2018.

(36) McEldrew, M.; Goodwin, Z. A. H.; Kornyshev, A. A.; Bazant, M. Z. Theory of the Double Layer in Water-in-Salt Electrolytes. J. Phys. Chem. Lett. 2018, 9 (19), 58405846.

(37) Yang, C.; Chen, J.; Qing, T.; Fan, X.; Sun, W.; Cresce, A. von; Ding, M. S.; Borodin, O.; Vatamanu, J.; Schroeder, M. A.; et al. 4.0 V Aqueous Li-Ion Batteries. Joule 2017, $1(1), 122-132$. 